\title{
Pengaruh Knowledge Management dan Talent Management terhadap Pengembangan Karir Karyawan
}

\author{
Hani Darmawati* \\ Prodi Manajemen, Fakultas Ilmu Ekonomi dan Bisnis, Universitas Islam \\ Bandung, Indonesia. \\ *Hanidarmawati09@gmail.com
}

\begin{abstract}
This study aims to; 1) To determine Knowledge Management in KPSBU Lembang; 2) To know Talent Management in KPSBU Lembang; 3) Knowing Employee Career Development in KPSBU Lembang. The sampling technique is saturated sampling. This research use descriptive and verification methods with the number of respondents as many as 67 people using data collection techniques in field research and library research. The result of this study concluded that; 1) Knowledge Management at KPSBU Lembang is included in the high category; 2) Talent Management at KPSBU Lembang is quite good; 3) Employee Career Development is quite good; 4) Knowledge Management affects Employee Career Development; 5) Talent Management affect Employee Career Development; 6) Knowledege Management and Talent Management affect Employee Career Development. In conclusion is a Knowledge Management and Talent Management based on Employee Career Development at KPSBU Lembang.
\end{abstract}

Keywords: Knowledge Management, Talent Management, Employee Career Development

\begin{abstract}
Abstrak. Penelitian ini bertujuan untuk 1) Mengetahui Knowledge Management di KPSBU Lembang. 2) Untuk Mengetahui Talent Management di KPSBU Lembang. 3) Mengetahui Pengembangan Karir Karyawan di KPSBU Lembang. Teknik penarikan sampel adalah sampling jenuh. Penelitian ini menggunakan metode deskriptif dan metode verifikatif dengan jumlah responden sebanyak 76 orang menggunakan teknik pengumpulan, penelitian lapangan dan penelitian kepustakaan. Hasil penelitian ini menyimpulkan bahwa : 1) Knowledge Management di KPSBU Lembang termasuk kategori Tinggi; 2) Talent Management di KPSBU Lembang cukup baik; 3) Pengembangan Karir Karyawan di KPSBU Lembang cukup baik; 4) Knowledge Management berpengaruh signifikan terhadap Pengembangan Karir Karyawa; 5) Knowledge Management berpengaruh terhadap pengembangan karir karyawan 6) Talent Management berpengaruh terhadap Pengembangan Karir Karyawan. Kesimpulannya terdapat pengaruh antara Knowledge Managenet dan Talent Managent terhadap Pengembangan Karir Karyawan.
\end{abstract}

Kata Kunci: Knowledge Management, Talent Management, Pengembangan Karir Karyawan. 


\section{A. Pendahuluan}

Sumber daya manusia merupakan faktor yang mutlak diperlukan dalam suatu organisasi, baik pada instansi pemerintah, perusahaan, atau pada usaha-usaha sosial dimana ia mendapatkan suatu balas jasa atau imbalan tertentu. Perkembangan dunia usaha akan terealisasi apabila ditunjang oleh sumber daya manusia yang berkualitas. Perkembangan ilmu pengetahuan dan teknologi informasi pada era globalisasi saat ini, mendorong organisasi untuk mampu menganalisis dan mengantispasi setiap perubahan lingkungan atau iklim bisnis dengan memberikan respon yang tanggap secara cepat, tepat, efektif, dan efisien, oleh karena itu setiap organisasi dituntut untuk memiliki Sumber Daya Manusia (SDM) yang handal dan berkualitas untuk melakukan kegiatan operasional organisasi.

Kinerja karyawan akan mencapai hasil lebih maksimal apabila didukung knowledge (pengetahuan) yang dimilikinya. Torabi (2016). Menurut Dalkir (2011:4), Knowledge Management adalah sebuah koordinasi sitematis dalam sebuah organisasi yang mengatur sumber daya manusia, teknologi, proses dan struktur organisasi dalam rangka meningkatkan value melalui penggunaan ulang dan inovasi. Sedangkan Menurut Walczak dalam Intezari (2017:474) mendefinisikan Knowledge Management sebagai setiap proses (baik kebijakan formal atau metode pribadi informal) yang memfasilitasi penangkapan, distribusi, pembuatan dan penerapan pengetahuan untuk pengambilan keputusan. Knowledge Management dapat meningkatkan keahlian dan motivasi kerja sehingga mendorong peningkatan kinerja individu dan organisasi. Kinerja karyawan akan mencapai hasil lebih maksimal apabila didukung knowledge (pengetahuan) yang dimilikinya.

Proses pengembangan pengetahuan karyawan tidak lepas kaitannya dengan pengelolaan talenta yang tepat. Perusahaan yang baik adalah perusahaan yang visi, misi dan nilai perusahaan yang telah ditetapkan sebelumnya dijalankan oleh sejumlah pegawai yang bertalenta yang bekerjasecara bersama-sama dan bersinergi (Pella \& Afifah, 2011:70). Yarnall (2011:4) mengatakan bahwa manajemen talenta mencakup pemilihan dan pengembangan karyawan yang dianggap berbakat di dalam perusahaan sehingga dapat menghasilkan sekelompok orang yang dapat dikembangkan bakatnya untuk menjadi sebuah investasi dalam perusahaan. Capelli (2009; dalam Andry 2011) berpendapat bahwa: "Talent management berkaitan dengan mencari orang yang tepat dengan keterampilan yang tepat untuk posisi yang tepat." Pengembangan karyawan didalam perusahaan juga sangat menunjang keberhasilan perusahaan tersebut. Dalam pengembangan karyawan melalui pelatihan dan pendidikan adalah usaha yang terencana dari organisasi untuk meningkatkan pengetahuan, keterampilan, dan kemampuan karyawan. Begitu juga dengan pengembangan karir karyawan dalam perusahaan tersebut

Pengembangan karir karyawan bukan merupakan tangung jawab pegawai saja tetapi merupakan bagian dari tangung jawab organisasi dimana pegawai itu bekerja. Untuk melakukan pengembangan karier pegawai di sebuah instansi selain membuat perencanan karier pegawai, manajemen karier juga harus di perhatikan oleh organisasi dimana pegawai tersebut bekerja. Ike Kusdya Rachmawati (2008: 136) mengemukakan bahwa keterlibatan suatu organisasi dalam pengembangan karier pegawai adalah suatu organisasi adalah suatu keharusan. Byars dan Rue (2013) dalam penelitiannya mengemukan bahwa pengembangan karir merupakan aktivitas formal dan berkelanjutan yang merupakan suatu upaya dari organisasi untuk mengembangkan memperkaya sumber daya manusia dengan menyelaraskan kebutuhan mereka dengan kebutuhan organisasi.

Penelitian ini dilakukan untuk mengetahui penerapan Knowledge Management dan Talent Management Terhadap Pengembangan Karir Karyawan di Koperasi Peternak Susu Bandung Utara (KPSBU) yang terletak di Kecamatan Lembang Kabupaten Bandung Barat. KPBU merupakan koperasi primer tunggal usaha di kecamatan Lembang yang merupakan suatu wadah bagi para petani peternak sapi perah dengan wilayah kerja meliputi wilayah Lembang. KPSBU mempunyai beberapa produk yang dihasilkan, dalam sehari KPSBU mampu memproduksi 3000 Liter atau sekitar 6000 cup.

Fenomena yang terjadi di KPSBU Lembang terutama pada karyawannya dimana karyawan masih kurang mampu memahami tentang lingkup pekerjaannya terutam pengelolaan 
soft skill yang baik. Dalam hal ini menjadikan karyawan KPSBU Lembang tidak memiliki daya saing karna kenaikan jabatan tidak ditentukan oleh kemampuan dan pengetahuan yang dimiliki oleh karyawan itu sendiri. Selain itu, kinerja karyawan KPSBU tidak dinilai dari kemampuan ia melakukan dan menyelesaikan pekerjaannya sehingga karyawan tidak memiliki daya saing didalam perusahaan hal tersebut menjadikan perusahaan tidak kompeten dalam menyeleksi karyawannya. hal tersebut juga menjadikan tidak adanya kesesuaian antara pekerjaan yang dilakukan dengan skill yang dimiliki sehingga karyawan perlu beradaptasi lebih lama untuk menyesuaikan dengan lingkup pekerjaannya. Saat ini sistem pengolahan sumber daya manusia di KPSBU Lembang lebih menekankan pada masa kerja karyawan dibandingkan dengan prestasi atau kinerja yang telah dicapai dalam bentuk promosi atau keniakan golongan pada karyawan. Sehingga menjadikan perusahaan tidak konsisten dalam penerapan Knowledge Management dan Talent Management dalam proses perekrutan dan pengembangan karir bagi karyawannya.

Di KPSBU sendiri pengembangan karir karyawan atau kenaikan jabatan tidak tentu kapan akan dilakukan karna tidak adanya perencanaan karir yang jelas sehingga menjadikan karyawan tidak bisa memprediksi kapan karyawan tersebut akan mendapatkan promosi atau kenikan jabatan karena sistem yang di lakukan oleh perusahaan tersebut adalah menempati posisi yang kosong saat dibutuhkan, karyawanpun tidak akan tahu jenjang karir kedepannya seperti apa dan akan naik menjadi posisi apa. Hal tersebut dikarenakan metode pengembangan karir yang diterapkan tidak terencana.

\section{B. Landasan Teori}

\section{Lokasi Penelitian}

KPSBU Lembang bertempatan di Kompleks Pasar Panorama Lembang, Bandung Jawa Barat.

\section{Populasi dan Sampel}

Menurut Arikunto (2013:173) populasi adalah keseluruhan dari subjek penelitian. Jadi yang dimaksud populasi adalah individu yang memiliki sifat yang sama walaupun presentase kesamaannya itu sedikit, atau dengan kata lain seluruh individu yang akan dijadikan sebagai objek penelitian. Populasi penelitian ini adalah jumlah karyawan yang bekerja di KPSBU Lembang sebanyak 275 orang karyawan tetap dan 35 orang sebagai karyawan kontrak. Jumlah sampel tersebut diperoleh dari perhitungan yang ditemukan oleh Slovin dan Husain (2003:146) :

$$
\begin{aligned}
& \mathrm{n}=\mathrm{N} \\
& 1+\mathrm{Ne}^{2}
\end{aligned}
$$

Dimana :

$\mathrm{n}=$ Ukuran sampel

$\mathrm{N}$ = Ukuran populasi yaitu jumlah karyawan Kantor Pusat KPSBU Lembang

$\mathrm{e}^{2}=$ Persen kelonggaran ketidaktelitian karena kesalahan pengambilan

Dari jumlah populasi 310 karyawan maka teknik sampling menggunakan rumus likert diperoleh hasil:

$$
n=\frac{310}{1+310(10 \%)^{2}}=76
$$

Dengan demikian, jumlah sampel yang digunakan sebagai responden dalam penelitian ini sebanyak 76 karyawan Koperasi Peternak Susu Bandung Utara Lembang. Jumlah sampel tiap unit atau bagian sebagai berikut:

\section{Variabel Penelitian dan Definisi Operasional}

Adapun yang menjadi variabel dalam penelitian ini adalah sebagai berikut:

1. variabel bebas (Independen):

$\mathrm{X}_{1}$ : Knowledge Management 
$\mathrm{X}_{2}$ : Talent Management

2. variabel terikat (Dependen)

(Y) : Pengembangan Karir Karyawan

\section{Definisi Operasional}

1. Knowledge management

Menurut Becerra-Fernandez dan Sabherwal (2010), yang mengacu pada cara organisasi menangani pengetahuan pada berbagai tahap kehidupannya dalam sebuah organisasi. Ada empat proses utama:
a. Knowledge Discovery (Penemuan Pengetahuan)
b. Knowledge Capture (Penangkapan Pengetahuan)
c. Knowledge Sharing (Berbagi Pengetahuan)
d. Knowledge Application (Penerapan Pengetahuan)

2. Talent Management

Talent Management berkaitan dengan mencari orang yang tepat dengan keterampilan yang tepat untuk posisi yang tepat. Terdapat tiga pengukuran dari talent management menurut Capelli (2010):
a. Recruitment
b. Retain
c. Developing

3. Pengembangan Karir Karyawan

Pengembangan karir merupajan suatu proses dimana seorang karyawan merencanakan karir dan mengimplementasikan untuk tujuan karirnya dan bagaimana sebuah perusahaan merancang dan mengimplementasikan program pengembangan karirnya. Menurut Henry Simamora (2012:412), dimensi dan indikator pengembangan karir meliputi :
a. Mutasi
b. Seleksi
c. Penempatan

\section{Teknik Pengumpulan Data}

1. Data Primer

Dalam penelitian ini, penulis mengumpulkan data dengan turun secara langsung untuk meninjau dan meneliti ke perusahaan yang menjadi objek penelitian dengan cara:

a. Wawancara

b. Angket/Kuesioner

2. Data Sekunder

Dalam penelitian ini, peneliti memperoleh data melalui media perantara atau secara tidak langsung yang berupa buku, catatan, bukti yang telah ada atau arsip yang dipublikasikan maupun yang tidak dipublikasikan secara umum. contohnya Study Pustaka (Library Research).

\section{Hasil Penelitian dan Pembahasan}

\section{Uji Regresi Linier Berganda}

Tabel 1. Uji Regresi Linier Berganda

Coefficients $^{a}$

\begin{tabular}{|c|c|c|c|c|c|c|c|}
\hline \multirow[b]{2}{*}{ Model } & \multicolumn{2}{|c|}{$\begin{array}{l}\text { Unstandardized } \\
\text { Coefficients }\end{array}$} & \multirow{2}{*}{$\begin{array}{l}\text { Standardized } \\
\text { Coefficients } \\
\text { Beta }\end{array}$} & \multirow[b]{2}{*}{$\mathrm{T}$} & \multirow[b]{2}{*}{ Sig. } & \multicolumn{2}{|l|}{$\begin{array}{l}\text { Collinearity } \\
\text { Statistics }\end{array}$} \\
\hline & $B$ & Std. Error & & & & Tolerance & VIF \\
\hline 1 (Constant) & 9,853 & 1,723 & & 5,719 &, 000 & & \\
\hline $\mathrm{X} 1$ & ,167 &, 080 & 272 & 2,086 &, 040 & 340 & 2,938 \\
\hline $\mathrm{X} 2$ & ,465 & ,116 &, 521 & 3,990 & ,000 & ,340 & 2,938 \\
\hline
\end{tabular}

a. Dependent Variable: $Y$ 
Dari hasi SPSS dapat dijelaskan sebagai berikut:

$$
Y=9,853+0,167 x_{1}+0,465 x_{2}+e
$$

Berdasarkan hasil persamaan regresi tersebut, maka dapat diinterprestasikan Knowledge Managemet (X1) berpengaruh positif terhadap Pengembangan Karir Karyawan (Y) dengan koefisien regresi sebesar 0,167 dan Talent Management (X2) berpengaruh positif terhadap Pengembangan Karir Karyawan (Y) dengan koefisien regresi sebesar 0,465.

\section{Pengujian Hipotesis}

Uji T

1. Didapat koefisien korelasi Knowledge management $\left(\mathrm{X}_{1}\right)$ dengan Pengembangan Karir Karyawan (Y) sebesar 0,696 yang artinya ada hubungan yang kuat Knowledge management $\left(\mathrm{X}_{1}\right)$ Terhadap Pengembangan Karir Karyawan $(\mathrm{Y})$.

2. Talent Managemet (X1) berpengaruh positif terhadap Pengembangan Karir Karyawan (Y) dengan koefisien regresi sebesar 0,167 dan Talent Management (X2) berpengaruh positif terhadap Pengembangan Karir Karyawan (Y) dengan koefisien regresi sebesar 0,465 .

Uji F

Tabel 2. Pengaruh Variabel Knowledge Management dan Talent Management Terhadap Pengembangan Karir Karyawan

\begin{tabular}{|c|c|c|c|c|c|c|}
\hline \multicolumn{7}{|c|}{ ANOVA $^{a}$} \\
\hline & & Sum of Squares & $D f$ & Mean Square & $\mathrm{F}$ & Sig. \\
\hline \multirow[t]{3}{*}{1} & Regression & 1353,882 & 2 & 676,941 & 49,637 &, $000^{\mathrm{b}}$ \\
\hline & Residual & 995,552 & 73 & 13,638 & & \\
\hline & Total & 2349,434 & 75 & & & \\
\hline
\end{tabular}

a. Dependent Variable: $Y$

b. Predictors: (Constant), X2, X1

Hasil perhitungan pada table anova, menunjukan nilai $\mathrm{f}_{\text {hitung }}$ adalah 49,637 dengan signifikansi $=0,000$. Pengujian dengan membandingkan signifikansi $=0,000$ dengan $\alpha=5 \%$ $(0,05)$ maka $0,000<0,05$ artinya Ho ditolak dan Ha diterima. Apabila pengujian dengan membandingkan $\mathrm{f}_{\text {hitung }}=49,637>\mathrm{f}_{\text {tabel }}=3,12$ maka Ho ditolak dan Ha diterima. Oleh karena itu dapat disimpulkan bahwa terdapat pengaruh yang signifikan dari Knowledge Management dan Talent Management Terhadap Pengembangan Karir Karyawan.

\section{Kesimpulan}

1. Berdasarkan pengujian hipotesis, karena nilai t-hitung lebih besar dari t-tabel maka Ho dan Ha diterima, artinya terdapat pengaruh siginfikan antara Knowledge Management terhadap Pengembangan Karir Karyawan.

2. Berdasarkan pengujian hipotesis, karena nilai t-hitung lebih besar dari t-tabel maka Ho dan Ha diterima, artinya terdapat pengaruh signifikan antara Talent Management terhadap Pengembangan Karir Karyawan.

3. Berdasarkan hasil penelitian dan pengujian hipotesis secara simultan, Karena nilai $t_{\text {hitung }}$ lebih besar dari $t_{\text {tabel }}$ maka Ho dan Ha diterima. Maka dapat disimpulkan bahwa terdapat pengaruh yang siginfikan dari Knowledge Management dan Talent Management terhadap Pengembangan Karir Karyawan di Koperasi Peternak Susu Bandung Utara Lembang.

\section{Daftar Pustaka}

[1] Torabi, M.H.R., Kyani, A., \& Hussein, F. (2016). An Investigation of the Impact of

[2] Knowledge Management on Human Resource Performance in Management of Keshavarzi Bank Branches in Tehran. Procedia - Social and Behavioral Sciences. 
[3] Rivai, V dan Sagala E.J. 2013. Manajemen Sumber Daya Manusia untuk Perusahaan

[4] Dari Teori ke Praktik, Edisi Kedua. Cetakan Kelima. Jakarta: PT. Raja Grafindo Persada

[5] Sugiyono. 2010. Metode Penelitian Pendekatan Kuantitatif, Kualitatif, dan R\&D. Bandung: Alfabeta

[6] Yarnall, Jane. 2011. Maximising the effectiveness of talent pools: a review of case study literature. Leadership \& organization Development Journal.

[7] Capelli, Peter. (2009). Talent on Demand. Metode Baru Mendapatkan SDM

[8] Bertalenta Tepat Jumlah, Tepat Kualifikasi, dan Tepat Waktu. Diterjemahkan oleh Wendra Triana Rafelina. Jakarta: PPM.

[9] Pella, Darmin Ahmad \& Afifah Inayati. (2011). Talent Management

[10] Mengembangkan SDM untuk Mencapai Pertumbuhan dan Kinerja Prima. Jakarta: PT.Gramedia 